\title{
Funding the new biologics - CCOHTA report on the cost effectiveness of infliximab for Crohn's disease: Pearls and pitfalls
}

\author{
John K Marshall MD MSc FRCPC
}

JK Marshall. Funding the new biologics - CCOHTA report on the cost effectiveness of infliximab for Crohn's disease: Pearls and pitfalls. Can J Gastroenterol 2002;16(12):877-879.

The Canadian Coordinating Office for Health Technology Assessment (CCOHTA) published an economic analysis, using a Markov model, of infliximab therapy for Crohn's disease that is refractory to other treatments. This was the first fully published economic analysis that addresses this treatment option. Health state transitions were based on data from Olmsted County, Minnesota, health state resource profiles were created using expert opinion and a number of assumptions were made when designing the model. The analysis was rigorous, the best available efficacy and safety data were used, state-of-the art sensitivity analyses were undertaken and an 'acceptability curve' was constructed. The model found that infliximab was effective in increasing quality-adjusted life years when offered in a variety of protocols, but it was associated with high incremental cost utility ratios compared with usual care. The results should be interpreted, however, in view of a number of limitations. The time horizon for the analysis was short (one year), because of a lack of longerterm efficacy data, and might have led to an underestimation of the benefits from averting surgery. Because the analysis was performed from the perspective of a Canadian provincial ministry of health, only direct medical costs were considered. Patients with active Crohn's disease are likely to incur significant indirect costs, which could be mitigated by this medication. The analysis should be updated as new data become available. Moreover, small changes in the cost of the medication could make the treatment cost effective, according to this model. Economic analyses, such as the one undertaken by the CCOHTA, cannot by themselves solve dilemmas in the allocation of limited health care resources, and other considerations must be included when formulating policy. This is especially important for patients with severe Crohn's disease, who have significant disability and for whom few therapeutic options exist.

Key Words: Cost effectiveness; Cost-utility; Crohn's disease; Economics; Inflammatory bowel disease; Infliximab; Tumour necrosis factor-alpha

\section{Rapport de l'OCETS sur le rapport coût-effi- cacité de l'infliximab dans le traitement de la maladie de Crohn : forces et faiblesses}

RÉSUMÉ : L'Office canadien de l'évaluation des technologies de santé (OCETS) a publié une analyse économique faisant appel à un modèle de Markov et portant sur le traitement par l'infliximab de la maladie de Crohn rebelle aux autres traitements. Il s'agit de la première analyse économique publiée en entier sur cette option thérapeutique. Les transitions d'états de santé étaient basées sur des données recueillies dans le Olmsted County, au Minnesota; les profils de ressources des états de santé ont été créés à partir de l'opinion de spécialistes; et un certain nombre de postulats ont été faits pendant la conception du modèle. C'est une analyse rigoureuse : les auteurs ont utilisé les meilleures données d'efficacité et d'innocuité disponibles, ils ont effectué des analyses de sensibilité d'avant-garde et ils ont présenté une « courbe d'acceptabilité ». D'après ce modèle, l'infliximab est efficace car il augmente le nombre d'années-personnes sans invalidité selon divers protocoles. Cependant, il est associé à des rapports coût-utilité plus élevés que les options classiques. Les résultats doivent être interprétés à la lumière d'un certain nombre de limites.

suite à la page suivante

Presented at a workshop held at the University of Calgary, September 24, 2002. The workshop was supported by an unrestricted grant from Schering Pharmaceuticals, Pointe-Claire, Quebec

Division of Gastroenterology, McMaster University, Hamilton, Ontario

Correspondence: Dr John K Marshall, Division of Gastroenterology (4W8), McMaster University Medical Centre, 1200 Main Street West,

Hamilton, Ontario L8N 325. Telephone 905-521-2100 extension 76782, fax 905-521-4958, e-mail marshllj@mcmaster.ca 
L'horizon prévisionnel de cette analyse était court (un an) en raison du manque de données d'efficacité sur de plus longues périodes, et aurait pu entraîner une sous-estimation des avantages d'éviter la chirurgie. Comme l'analyse a été effectuée dans l'optique d'un ministère provincial (canadien) de la Santé, seuls les coûts médicaux directs ont été pris en compte. Or, les cas de maladie de Crohn active occasionnent également des coûts indirects notables, qui pourraient être réduits par ce médicament. Cette analyse devrait être mise à jour à mesure que de nouvelles données seront disponibles. De plus, selon ce modèle, le traitement pourrait présenter un rapport coût-efficacité acceptable si de légers changements étaient apportés au coût du médicament. Les analyses économiques, comme celle qui a été entreprise par l'OCETS, ne peuvent à elles seules résoudre les dilemmes liés à l'affectation des ressources limitées dans le domaine de la santé. Il faut prendre en compte divers autres facteurs dans l'élaboration de politiques. Ces considérations concernent particulièrement le cas des patients souffrant d'une forme grave de la maladie de Crohn, qui entraîne une invalidité importante et pour laquelle il existe peu d'options thérapeutiques.
Tnfliximab, a monoclonal antibody to tumour necrosis fac1 tor (TNF)-alpha, is approved in Canada for the treatment of Crohn's disease that is either refractory to other medical treatments or complicated by enterocutaneous fistulas. Efficacy for each of these indications has been documented in well-designed clinical trials, and its use has been endorsed by consensus guidelines (1). Indeed, for patients with difficult intestinal symptoms and few treatment options, infliximab is a welcome option. However, physicians, patients, insurers and policy advisors have been forced to weigh the obvious appeal of infliximab against its cost, estimated to exceed $\$ 5000$ per dose for a $70 \mathrm{~kg}$ patient (2). With recent clinical trials advocating an intensive three-dose induction regimen and repeat infusions every eight weeks to maintain remission (3), the costs of treatment are substantial. Therefore, the use of infliximab would make good economic sense only if gains in health and quality of life are sufficient to justify its cost, or if that cost could be offset by the avoidance of hospitalizations or surgery, reductions in the requirement for other medications or the return of patients to productive employment.

To understand better the tradeoffs in costs and benefits associated with infliximab therapy in a Canadian practice setting, the Canadian Coordinating Office of Health Technology Assessment (CCOHTA) commissioned an economic evaluation of its use in Crohn's disease that is resistant to conventional medical therapy (2). The full report of this analysis can be obtained through the CCOHTA Web site (www.ccohta.ca). The investigators (including this author) constructed a Markov model to compare the expected costs and health outcomes of four alternative treatment regimens over one year, from the perspective of a Canadian provincial ministry of health. The strategies were: usual care (modeled as a weighted mixture of outpatient and inpatient medical care and admission for surgery); a single infusion of infliximab; a single infusion of infliximab with repeated treatments for subsequent relapses; and an initial infusion of infliximab followed by maintenance infusions every eight weeks for patients who respond. Direct medical costs (in 2001 Canadian dollars) were assessed from the perspective of a Canadian provincial Ministry of Health, and outcomes were measured in quality-adjusted life years (QALY). Given the short time horizon, neither costs nor effects were discounted.

The model's base-case analysis found usual care to be the least costly but least effective strategy. A single infusion of infliximab improved outcomes, but at an incremental cost of $\$ 181,201$ for each additional QALY gained. The re-treatment and maintenance strategies yielded progressively more QALY, but with substantially higher incremental cost-utility ratios (ICUR) of $\$ 480,111 /$ QALY and $\$ 696,078 /$ QALY, respectively. While the use of cost-perQALY benchmarks to direct health care funding decisions is highly controversial (4-6), thresholds from $\$ 20,000 /$ QALY to $\$ 100,000 /$ QALY have been proposed (4). By any of these criteria, the use of infliximab to improve health outcomes in patients with Crohn's disease is costly.

These results might not be surprising, given the high acquisition cost of infliximab itself. However, readers are cautioned to consider more than these bottom line numeric results when applying the economic model to clinical practice. Complete information never exists for determining the optimum treatment for individual patients or when formulating health care policy. Decision analysis utilizes the best available information to estimate the costs and outcomes of alternative strategies. In doing so, the decisionmaking process is made more explicit and key areas of uncertainty are illuminated. However, no decision model is perfect or immune from criticism. It is, therefore, essential that readers scrutinize the assumptions on which the model is designed, consider the certainty with which model parameters are defined, and judge the strength of its conclusions.

To its credit, the CCOHTA analysis is methodologically sound, uses state of the art techniques in its analysis and presentation, and remains the only fully published economic analysis of infliximab treatment relevant to a Canadian practice setting. In particular, both conventional stochastic sensitivity analysis and newer techniques of probabilistic sensitivity analysis were used to explore the effects of parameter uncertainty on the model's conclusions. The latter analysis yields an 'acceptability cure' that plots the probability that each strategy is the most cost effective across a range of cost-per-QALY thresholds. This innovative approach presents the key model results to decision makers without endorsing a particular cost-per-QALY ratio.

As with any cost utility Markov model, the CCOHTA analysis required three key data components to characterize each health state: estimated probabilities of 'transitioning' to other health states; profiles of resource utilization and costs accrued while in the state; and an estimate of the health state's relative value or 'utility'. For each data com- 
ponent, a number of key assumptions were made and are detailed in the CCOHTA report (2). For example, some parameters (eg, health state resource profiles) relied on expert opinion to compensate for a lack sufficiently detailed empirical data. For others, such as health state transitions in usual care, adequate data were available only from another jurisdiction (Olmsted County, Minnesota) (7). Similarly detailed data from a contemporary Canadian population would have been preferred, but were not available. Empirical Canadian data were available for other parameters, such as health state utilities (8). Assumptions were still required, however, to transpose those weights to the particular health states used in the CCOHTA model.

Several key aspects of the CCOHTA model's core structure should also be considered when interpreting its results. For example, a relatively short time horizon (one year) was chosen to mirror the follow-up period available from published clinical trials. Thus, more remote downstream benefits of infliximab therapy (such as the cumulative benefits of avoiding surgery) might have been under-represented. On the other hand, the long term efficacy of infliximab is not known. Despite its advantages in comparing cost effectiveness across programs, even the QALY can be criticized as a measure of health outcome for failing to capture and balance all dimensions of the health of Crohn's disease patients. Finally, the model was analyzed from the perspective of a provincial ministry of health and, as a result, considered only direct medical costs. It is well recognized that patients with active Crohn's disease incur considerable indirect costs $(9,10)$. If the model were restructured to consider a societal perspective, the capacity of infliximab ther-

\section{REFERENCES}

1. Fedorak RN. Canadian Association of Gastroenterology. Canadian Association of Gastroenterology clinical practice guidelines: The use of infliximab in Crohn's disease. Can J Gastroenterol 2001; 15:367-70.

2. Marshall JK, Blackhouse G, Goeree R, et al. Infliximab for the treatment of Crohn's disease: A systematic review and cost-utility analysis. Ottawa: Canadian Coordinating Office for Health Technology Assessment; 2002. Technology Report No 24.

3. Hanauer SB, Feagan BG, Lichtenstein GR, et al. Maintenance infliximab for Crohn's disease: The ACCENT I randomised trial. Lancet 2002;359:1541-9.

4. Laupacis A, Feeny D, Detsky AS, Tugwell PX. How attractive does a new technology have to be to warrant adoption and utilization? Tentative guidelines for using clinical and economic evaluations. Can Med Assoc J 1992;146:473-81.

5. Gafni A, Birch S. Guidelines for the adoption of new technologies: apy to return some patients to productive employment could make its use more economically attractive.

It is especially important to emphasize that the CCOHTA infliximab model, like any economic analysis, must be continually updated from the moment of publication. Readers must reinterpret results as new data on efficacy and toxicity emerge, and in light of other therapeutic advances. Gains in efficacy offered by more intensive dosing schedules (like those used in the recent ACCENT I trial [3]), must be balanced against substantial increases in medication cost. Moreover, relatively small changes in drug costs could dramatically influence the net incremental costs of infliximab treatment. In the CCOHTA model, for example, a 25\% reduction in the cost of infliximab reduced the incremental cost utility ratio of a single infusion below $\$ 100,000 / \mathrm{QALY}$, compared with usual care.

\section{CONCLUSIONS}

In summary, the CCOHTA cost-utility analysis is methodologically rigorous, and remains the only fully published economic model of the use of infliximab for refractory Crohn's disease. When interpreting its results, decision makers are encouraged to consider the many assumptions required for its design, and the strengths and limitations of its analysis. Like other economic models, the CCOHTA report does not single-handedly resolve policy dilemmas. At best, it helps to frame the problem and provides explicit data with which informed decisions can be made. When allocating precious health care resources, policy-makers must consider several dimensions, including compassion for patients with refractory disease and few treatment alternatives.

\footnotetext{
A prescription for uncontrolled growth in expenditures and how to avoid the problem. Can Med Assoc J 1993;148:913-7.

6. Briggs A, Gray A. Using cost effectiveness information. BMJ 2000;320:246.

7. Silverstein MD, Loftus EV, Sandborn WJ, et al. Clinical course and costs of care for Crohn's disease: Markov model analysis of a population-based cohort. Gastroenterology 1999;117:49-57.

8. Gregor JC, MacDonald JWD, Klar N, et al. An evaluation of sutility measurement in Crohn's disease. Inflamm Bowel Dis 1997;3:265-76.

9. American Gastroenterological Association. Chronic intestinal disorders. In: The Burden of Gastrointestinal Illness. Bethesda, Maryland: American Gastroenterological Association; 2001.

10. Blomqvist P, Ekbom A. Inflammatory bowel diseases: Health care and costs in Sweden in 1994. Scand J Gastroenterol 1997;32:1134-9.
} 


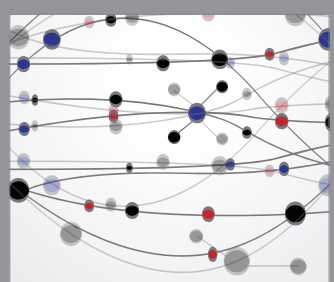

The Scientific World Journal
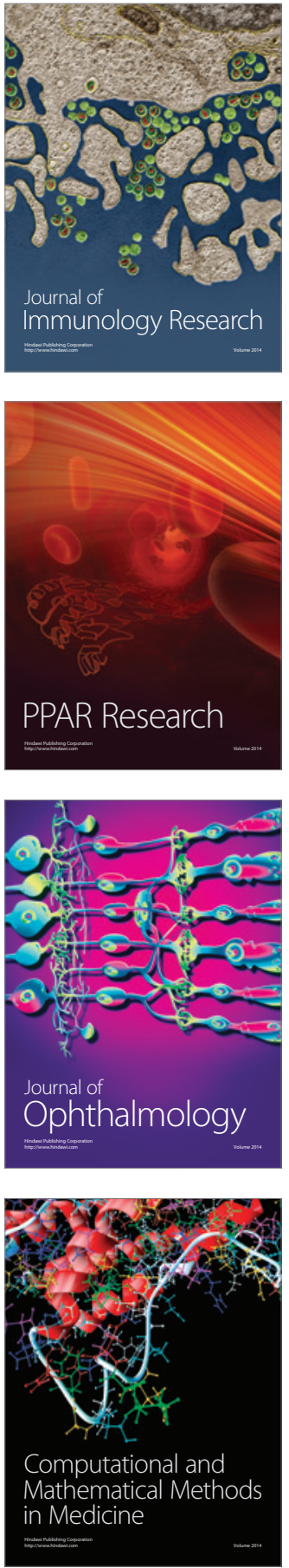

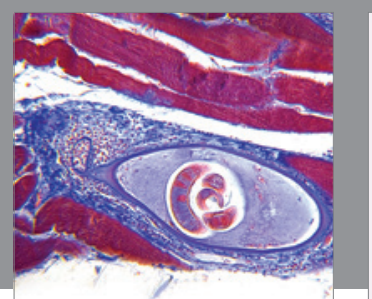

Gastroenterology Research and Practice

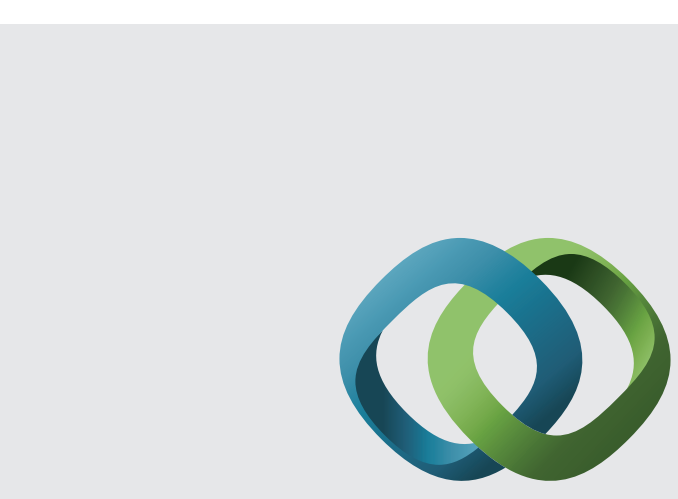

\section{Hindawi}

Submit your manuscripts at

http://www.hindawi.com
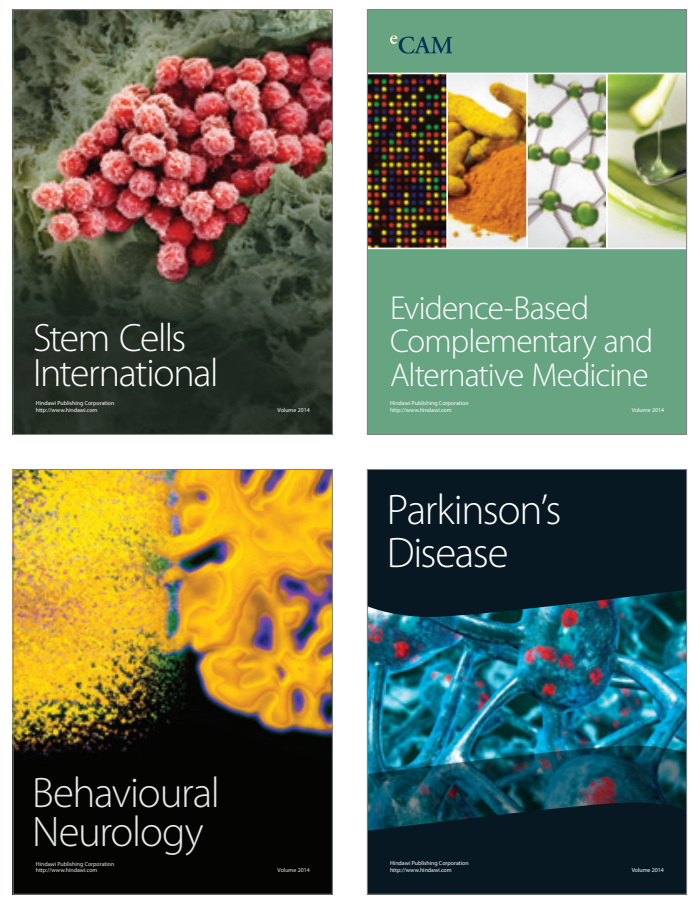
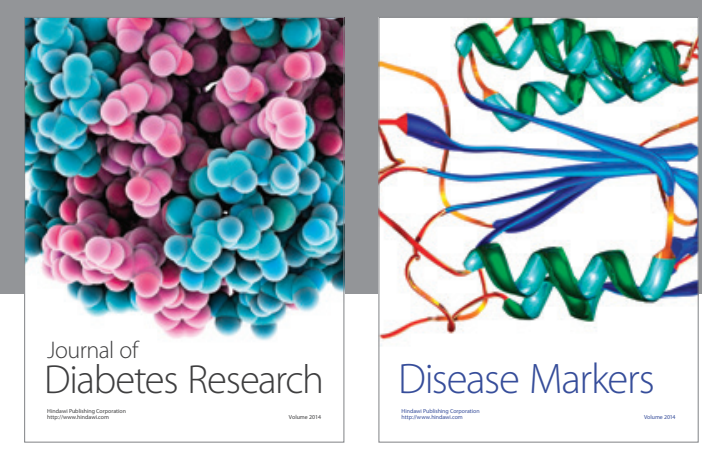

Disease Markers
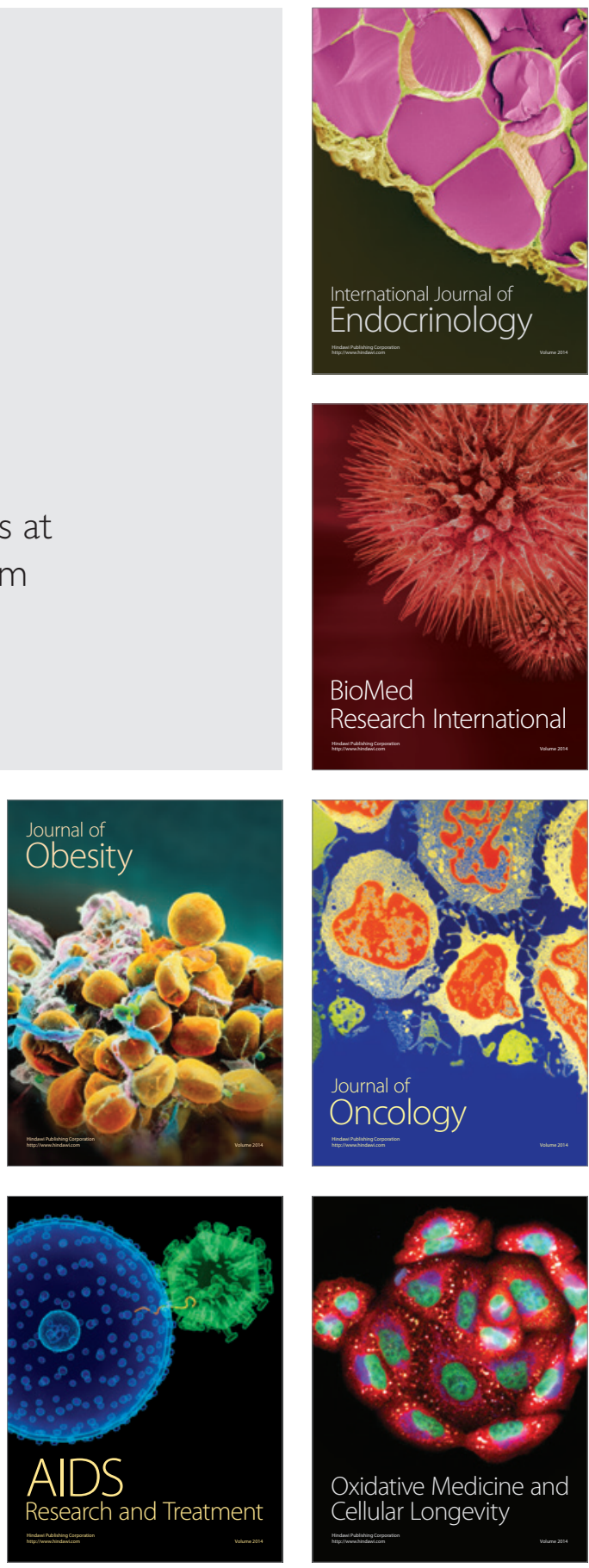